Research Article

\title{
Properties of Sn-Ag-Cu Solder Joints Prepared by Induction Heating
}

\author{
Marian Drienovsky (iD, Marián Palcut ${ }^{D}$, Pavol Priputen (iD, Eva Cuninková, \\ Ondrej Bošák $\mathbb{D}$, Marián Kubliha $\mathbb{D}$, and Lýdia Rízeková Trnková
}

\begin{abstract}
Slovak University of Technology in Bratislava, Faculty of Materials Science and Technology in Trnava, Institute of Materials Science, Jana Bottu 25, 91724 Trnava, Slovakia
\end{abstract}

Correspondence should be addressed to Marián Palcut; marian.palcut@stuba.sk

Received 26 November 2019; Revised 27 January 2020; Accepted 4 February 2020; Published 12 March 2020

Academic Editor: Sakar Mohan

Copyright (c) 2020 Marian Drienovsky et al. This is an open access article distributed under the Creative Commons Attribution License, which permits unrestricted use, distribution, and reproduction in any medium, provided the original work is properly cited.

\begin{abstract}
In the present work, one near-eutectic and three hypoeutectic $\mathrm{Sn}-\mathrm{Ag}-\mathrm{Cu}$ alloys have been employed for soldering by induction heating. The alloys were produced by induction melting of high purity $\mathrm{Ag}, \mathrm{Cu}$, and $\mathrm{Sn}$ lumps. The melting behavior of the alloys was investigated by differential scanning calorimetry. The solder alloys were subsequently applied for soldering by conventional hot-plate heating as well as induction heating and both soldering times and peak temperatures were recorded during soldering. Solder joints of two copper sheets were produced. The electrical resistance, tensile strength, and microstructure were analyzed on each soldered joint. The results indicate that the physical and mechanical properties of solder joints are determined by their chemical composition and soldering technology. Induction soldered joints not only have a slightly higher electrical resistivity but also higher mechanical strength, except of the $0.3 \mathrm{wt} . \% \mathrm{Ag}$ hypoeutectic solder. The highest increase in ultimate tensile strength (28\%) was observed for induction soldered joints with $1 \mathrm{wt} . \%$ Ag hypoeutectic solder. This effect is ascribed to the homogenous distribution of the intermetallic compounds within the eutectic in the alloy microstructure. The homogenous distribution is aided by rotation of liquid solder due to eddy currents and high-frequency magnetic field generated during induction heating.
\end{abstract}

\section{Introduction}

Ternary $\mathrm{Sn}-\mathrm{Ag}-\mathrm{Cu}$ alloys constitute a favorite replacement of traditional $\mathrm{Sn}-\mathrm{Pb}$ solders in many applications. The $\mathrm{Sn}-\mathrm{Ag}$ $\mathrm{Cu}$ solders have good wettability, solderability, and favorable mechanical and electrical properties. Furthermore, these materials are environmentally friendly as they lack heavy elements. Because of cost reductions, hypoeutectic alloys with low silver concentration have become increasingly popular. The hypoeutectic $\mathrm{Sn}-\mathrm{Ag}-\mathrm{Cu}$ alloys have a wider melting temperature range, worse wetting, coarse microstructure, and substandard mechanical strength in comparison with the eutectic solder alloy. Nevertheless, these drawbacks have been improved by microalloying with other metal elements located in the $\mathrm{d}$ - and f-group of the periodic table, as shown by both Sabri et al. [1] and Silva et al. [2]. Another approach has been to prepare quaternary alloys with p-group elements, as introduced by El-Daly et al. [3]. Moreover, Tu et al. reported that rare earth elements could be also utilized to form a more complex alloy [4]. It is generally recognized that certain amounts of fourth and/or fifth elements can improve various physical properties of this type of alloy. As we found in [5], the processing and utilization of such alloys could be hindered by oxidation of some of the alloying elements. This problem, however, could be prevented by dispersing oxide nanoparticles in the alloy. The oxide nanoparticles can contribute to the refinement of the alloy's microstructure and further improve the thermal and mechanical properties as reported by Zhao et al. [6] and Wen et al. [7].

As a result of the quest for the ideal lead-free solder, a number of different alloy compositions have been produced in the last decade [8-15]. Less attention, however, was paid to the improvement of the soldering process itself. The 
technology of wave soldering is probably the best option for large-scale manufacturing. The reflow soldering, on the other hand, has been mostly employed in the surface mounted assembling technology (SMT). With the mandatory utilization of lead-free alloys, both technologies face new challenges. These challenges include, for example, the corrosion susceptibility of the stainless-steel components in wave soldering, as was discussed by Xiao et al. [16], or an uneven temperature distribution in the reflow oven, which may result in various defects of the final product as reported by Deng et al. [17].

Induction heating is an innovative approach in the soldering technology. $\mathrm{Li}$ et al. were the first to introduce induction heating at reflow soldering [18]. This type of heating has an advantage of the intrinsic induction. The heat is produced directly in the metallic workpiece during induction heating. As such, the nonmetallic parts of the soldered electronics are only minimally heated $[19,20]$. Li et al. calculated and experimentally confirmed that the heat produced in the solder ball depends on its size and higher temperatures could be generated in larger solder balls [21]. This advantage was availed at selective reflow soldering. Moreover, both $\mathrm{Xu}$ et al. [22] and Lanin et al. [23] reported that, by the skin effect of the eddy current at high frequencies, it is possible to control the shape of the solder ball and its formation from soldering paste. Yang et al. recently showed that the evolution and orientation of $\mathrm{Cu}_{6} \mathrm{Sn}_{5}$ intermetallic compounds (IMCs) in the solder joint microstructure could be influenced by magnetic field [24]. Eddy currents are loops of electrical current induced in electrical conductors by magnetic field according to the law of induction. The explanation of how the electromagnetic force and related eddy currents interact with primary compounds in the melt can be found, for instance, in a recent work of Zhou et al. [25]. Generally, it is recognized that the application of alternating electromagnetic field during solidification can affect the solute and heat transport in the melt, which improves the resulting microstructure. More specifically, it reduces the gradient (imbalance) of the solute within the melt and this is performed by stirring of the melt by electromagnetic force. More homogenous melt is produced by application of the electromagnetic field, which thereby promotes a heterogeneous nucleation of primary compounds (IMCs in this case). Moreover, the IMCs in the melt are further stirred which prevents their agglomeration and additional growth. Regular distributions of IMC precipitates and their ability to inhibit a dislocation and crack propagation have been shown to improve the shear strength of solder joints [24]. Seehase et al. adopted the induction heating for selective soldering of printed circuit boards (PCBs) by using the flat pancake and cylindrical coil [26]. They showed that the soldered joints could be prepared at both geometries if an appropriate susceptor is applied. In a succeeding testing of soldered components, no errors were found. Yin et al. successfully utilized the same method for the fabrication of full IMC solder joints [27]. The rapid IMC growth has recently been aided by using an electromagnetic stirring effect [28].

Based on the aforementioned benefits, we recently applied this technology for joining of High-Temperature Superconducting (HTS) Tapes [29]. However, the quality of joints also depended on the chemical composition of the solder. To our best knowledge, there is no comparative investigation of reflow soldering by conduction heating with soldering by induction heating. Therefore, in this study we prepared four types of lead-free solder alloys with different Ag concentrations. The alloys were utilized for soldering by induction heating and the properties of solder joints were compared with those prepared by conductive heating. The electrical resistivity, ultimate tensile strength and microstructure of soldered joints have been investigated on the specimens prepared by both techniques.

\section{Materials and Methods}

2.1. Alloy Preparation and Characterization. Four alloys, Sn$0.3 \mathrm{Ag}-0.7 \mathrm{Cu}$ (denoted as SAC037, element concentrations given in wt.\%), Sn-1.0Ag-0.8Cu (SAC108), Sn-1.5Ag-0.8Cu (SAC158), and Sn-3.5Ag-0.7Cu (SAC357), were produced by melting of Sn, Ag, and Cu granules (purity of 99.99 wt.\%) in argon atmosphere. The melting was conducted in $\mathrm{Al}_{2} \mathrm{O}_{3}$ crucibles positioned inside a vacuum induction furnace. Before the experiment, the furnace was evacuated and rinsed with Ar gas (99.9999 vol. \%). A mechanical stirring with glass rod was used for homogenizing the alloys. Each alloy was solidified on a stainless-steel plate to form cast strips.

The phase constitution of the alloys was studied by Philips PW1830 X-ray diffractometer (XRD) with filtered CoK $\alpha 1$ radiation $(\lambda=0.178901 \mathrm{~nm})$. The scattering angle $(2$ theta) was varied between $30^{\circ}$ and $80^{\circ}$. The measurements were conducted with a step size of $0.05^{\circ}$ and the exposure time of $10 \mathrm{~s}$ per step.

JEOL JSM7600 F scanning electron microscope (SEM) was used to study the alloy's microstructure. Accelerating voltage of $20 \mathrm{kV}$ was applied during measurements. The chemical composition of the as-cast alloys was analyzed with energy-dispersive X-ray spectrometer (EDX). The EDX analysis was operated by INCA software.

The melting behavior was studied by differential scanning calorimetry (DSC). The samples were positioned in aluminum pans in a Netzsch STA 409CD instrument. The chamber was evacuated and rinsed with Ar before each experiment. The measurement was performed in flowing Ar (99.9999 vol. \%). Two samples were studied: one taken from the center and one from the edge position of the cast strips. The mass of each sample was approximately $5 \mathrm{mg}$. Each specimen was measured twice, to verify the reproducibility. A heating rate of $1 \mathrm{C} \cdot \mathrm{min}^{-1}$ was employed. In order to explain the DSC peaks of hypoeutectic solders, a thermodynamic modeling of the $\mathrm{Sn}-\mathrm{Ag}-\mathrm{Cu}$ system was performed by the CALPHAD approach (CALculation of PHAse Diagrams). These calculations were carried out by Thermo-Calc software employing the COST531 Lead-Free solder database [30].

2.2. Preparation of Solder Joints. The conventional soldering was performed in a small aluminum mold. The soldering by induction heating, on the other hand, was conducted in a plastic mold made of polytetrafluorethylene (PTFE). Both molds served as clamps. These clamps were applied to fix the 
position of the soldered $\mathrm{Cu}$ sheets. The aluminum mold was placed on a preheated hot plate (heat conductive reflow soldering) and specimens in PTFE mold were heat treated by a pancake inductor (made of solid Cu tube with $5 \mathrm{~mm}$ outer diameter). The high frequency electromagnetic field $(300 \mathrm{kHz})$ was generated by the Rajmont HFR15 induction device. Figure 1 documents the setup of the soldering process by induction heating. The plastic mold was positioned in the center of the device. A colophony diluted with isopropyl alcohol was used as flux for both soldering methods. After the peak soldering temperature was reached (approximately $10-20^{\circ} \mathrm{C}$ above liquidus temperature of the alloy), the molds with solder joints were rapidly solidified in cold water. The soldering temperature profiles, given in Figure 2, were measured by K-type thermocouples connected to datalogger unit. The measuring end of the thermocouple was connected to aluminum mold close to the solder joint of reflow-soldered samples. For induction soldered samples, the measuring end of the thermocouple was connected directly to the $\mathrm{Cu}$ sheet. The induction soldering process was very fast. The peak temperature $\left(235^{\circ} \mathrm{C}\right)$ was reached in less than $30 \mathrm{~s}$. It must be stated that this temperature profile (curve a) on Figure 2) was related to the heating of the $\mathrm{Cu}$ sheet rather than to the solder itself. The solder, which was originally in the form of little ball, was practically instantly melted when the power on the induction furnace was turned on. However, the liquid solder started to wet the surface of the $\mathrm{Cu}$ sheet only when the temperature of the $\mathrm{Cu}$ sheet was high enough. After solidification, the excess solder was removed by grinding and surface was carefully polished to reach the final geometry of the joints (Figure 3(a)). The dimensions of joint areas were measured by a digital caliper. A minimum of 5 specimens were prepared from each solder.

2.3. Electrical Resistivity Measurements. The electrical resistivity of joints was measured at room temperature. A Kelvin (four-wire) method was applied. By this method, the electrical resistance of the test leads was compensated, so the device could measure the voltage of the specimen. The measurements were performed by Keithley 2000 precision digital multimeter at room temperature since most applications are expected at ambient conditions.

2.4. Tensile Strength Determination and Microstructure Analysis. An appropriate model was designed (Figure 3(b)) in order to calculate the stress distribution in the soldered joints. The model was calculated by Finite Element Method (FEM) analysis integrated within Ansys software. The ultimate tensile strength of soldered joints was measured on a Micro-Epsilon UMZ-3k device. A strain rate of $2 \mathrm{~mm} \cdot \mathrm{min}^{-1}$ was used and the experiments were carried out at room temperature. During measurements, the load versus relative extension curves were recorded. The ultimate tensile strength (UTS) of each joint was calculated from the maximum force and cross section area of the solder joint.

After mechanical testing, the specimens were cold mounted in a conductive resin and subsequently

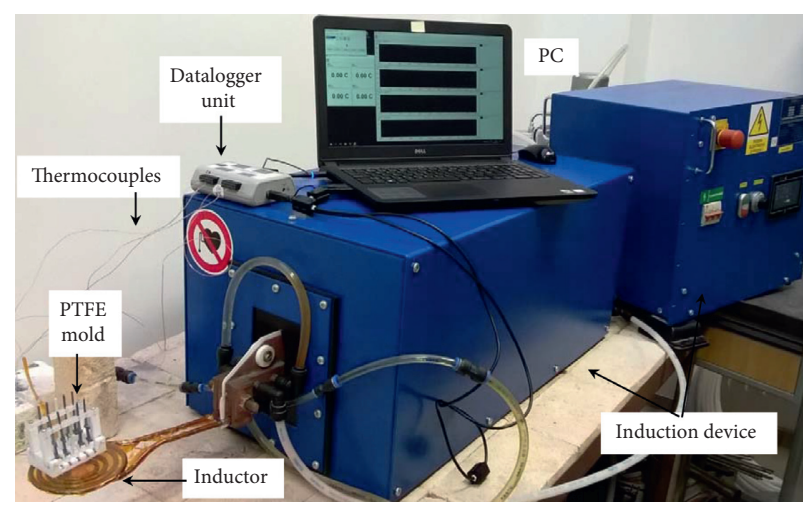

FIgURE 1: Experimental setup of soldering by induction heating.

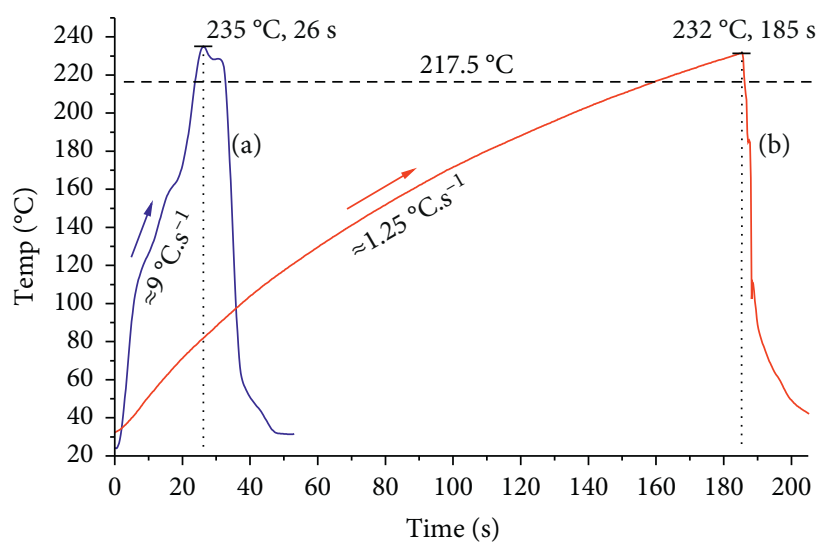

FIgURE 2: Time-temperature profiles of SAC alloy soldered by induction heating (a) and heat conductive reflow soldering method (b). $217.5^{\circ} \mathrm{C}$ is solidus temperature of solder alloys.

metallographically prepared by grinding and polishing for the microscopy observation. The crack propagation patch and deformation were studied by SEM coupled with EDX.

\section{Results and Discussion}

3.1. Solder Alloy Characterization. Chemical composition of solder alloys was analyzed by SEM-EDX. The chemical composition is presented in Table 1. The measurements were done on as-cast samples. Small variations in $\mathrm{Ag}$ and $\mathrm{Cu}$ concentrations were observed between the edge and central parts of the samples; however, this difference is attributable to a rapid solidification of the alloys. Overall, the agreement between the nominal element concentration and the measured concentration was satisfactory.

The phase constitution of the samples was studied by room temperature XRD analysis. The results are given in Figure 4 . The XRD patterns show the presence of three phases: $\beta$-Sn solid solution as a major phase and two intermetallic compounds $\left(\mathrm{Cu}_{6} \mathrm{Sn}_{5}\right.$ and $\left.\mathrm{Ag}_{3} \mathrm{Sn}\right)$. The intensity of $\mathrm{Ag}_{3} \mathrm{Sn}$ diffraction peaks was found to decrease with decreasing concentration of $\mathrm{Ag}$ in the solder alloy. The alloys examined in the present study had markedly different $\mathrm{Ag}$ concentrations. The majority of $\mathrm{Ag}$ was in the $\mathrm{Ag}_{3} \mathrm{Sn}$ intermetallic. Alloys with lower $\mathrm{Ag}$ content had a lower 


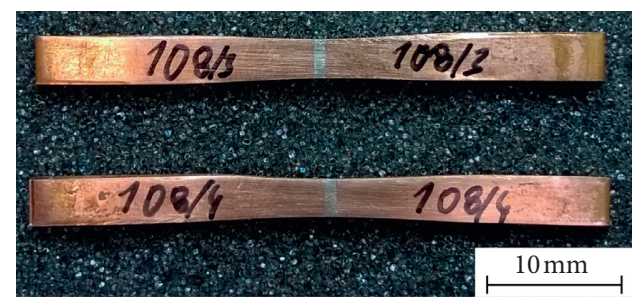

(a)

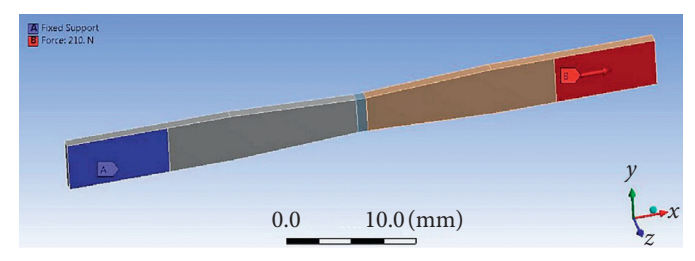

(b)

Figure 3: Final geometry of solder joints: an optical image (a) and FEM model (b).

TABle 1: Measured concentrations of $\mathrm{Ag}, \mathrm{Cu}$, and $\mathrm{Sn}$ in the solder alloys.

\begin{tabular}{lccc}
\hline \multirow{2}{*}{ Alloy } & \multicolumn{3}{c}{ Component (wt.\%) } \\
& $\mathrm{Ag}$ & $\mathrm{Cu}$ & $\mathrm{Sn}$ \\
\hline SAC357 & $3.26 \pm 0.08$ & $0.73 \pm 0.06$ & Bal. \\
SAC158 & $1.52 \pm 0.08$ & $0.82 \pm 0.09$ & Bal. \\
SAC108 & $1.06 \pm 0.11$ & $0.90 \pm 0.08$ & Bal. \\
SAC037 & $0.31 \pm 0.11$ & $0.70 \pm 0.10$ & Bal. \\
\hline
\end{tabular}

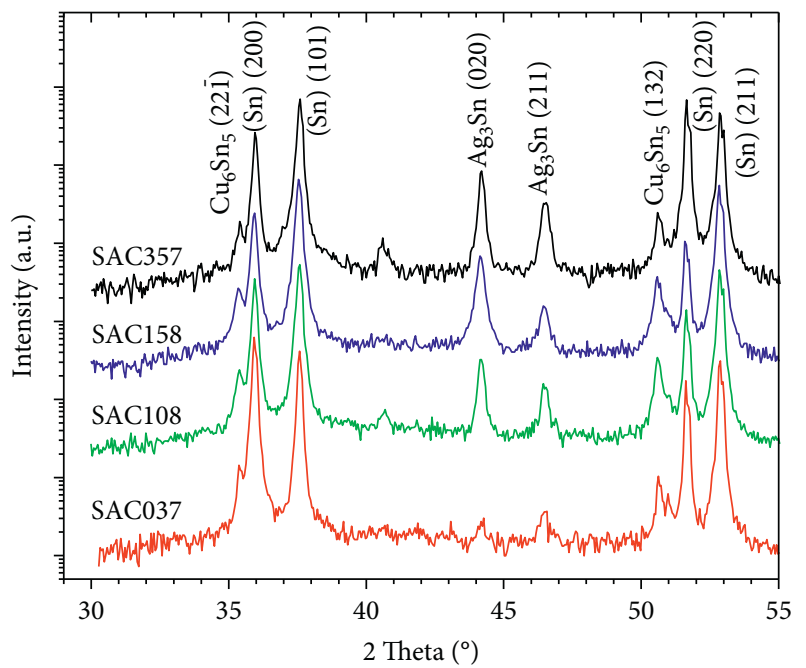

FIGURE 4: X-ray diffraction patterns of the SAC357, SAC158, SAC108, and SAC037 alloys.

concentration of $\mathrm{Ag}_{3} \mathrm{Sn}$ and thus the intensity of $\mathrm{Ag}_{3} \mathrm{Sn}$ diffraction peaks was decreasing with decreasing Ag concentration. These results are consistent with previous findings [1-7].

The DSC records of the solders are given in Figure 5. The first peak represents the melting of the eutectic. The data indicate that the eutectic melting point is $217.5 \pm 0.2^{\circ} \mathrm{C}$. This temperature is practically identical to the eutectic melting points determined by Moon et al. [31]. As suggested by Rycerz [32], the temperature of the last peak could be attributed to the liquidus temperature. The liquidus temperature depends on the Ag concentration in the alloy. Smaller Ag concentration is thus reflected in a higher liquidus temperature. The DSC record of the SAC037 alloy is noisier compared to the remainder of the alloys. This effect can be ascribed to the lower sample mass. The average mass of

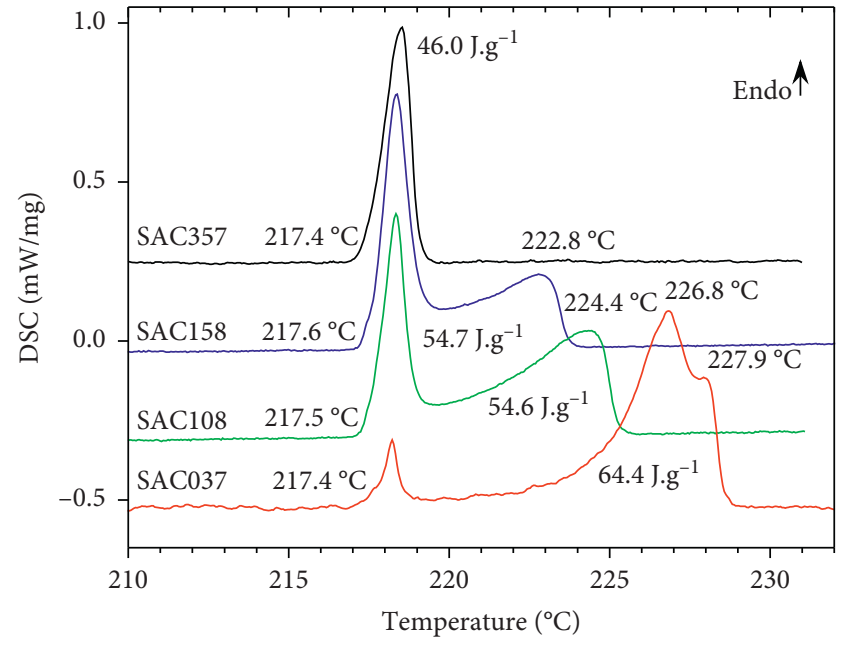

Figure 5: DSC records of the solder alloys.

samples was $5 \mathrm{mg}$; however, in order to increase the resolution of the DSC, the SAC037 sample had only $3 \mathrm{mg}$. The noise of the signal was thus higher compared to the remainder of the alloys.

A computational thermodynamic was used to describe the recorded melting peaks $[12,30,31]$. The vertical section diagrams, given in Figure 6(a) and Figure 6(b), indicate which phase melts at which temperature interval. For instance, the second endothermic peak in SAC037 solder (Figure 5) represents melting of the $\beta$-Sn solid solution and $\mathrm{Cu}_{6} \mathrm{Sn}_{5}$ intermetallic phase. The third peak at $227.9^{\circ} \mathrm{C}$ represents melting of the $\beta$-Sn solid solution (Figure $6(\mathrm{a})$ ). In case of SAC108 and SAC158 solders, the melting of Sn solid solution is not detectable by DSC because of very small temperature difference between two lines in the phase diagram (Figure 6(b)). A good agreement between the DSCdetermined solidus and liquidus temperatures for all systems is found (Figures 5 and 6). The only exception is the SAC357 solder where the measured Ag concentration was smaller ( $\approx 3.3 \mathrm{wt} . \%$, Table 1$)$ than $3.5 \mathrm{wt} . \%$ denoted in calculation. This small difference in Ag content causes a drop in liquidus temperature from $222^{\circ} \mathrm{C}$ to $218^{\circ} \mathrm{C}$, as it can be seen from Figure 6(a). Such observation is in a good agreement with the experimental DSC curve (Figure 5), where the liquidus temperature of the SAC357 solder alloy is found at $218.5^{\circ} \mathrm{C}$.

The enthalpy of fusion represents the amount of heat energy required to change the state of matter from solid to liquid. Therefore, it is an important parameter at all 


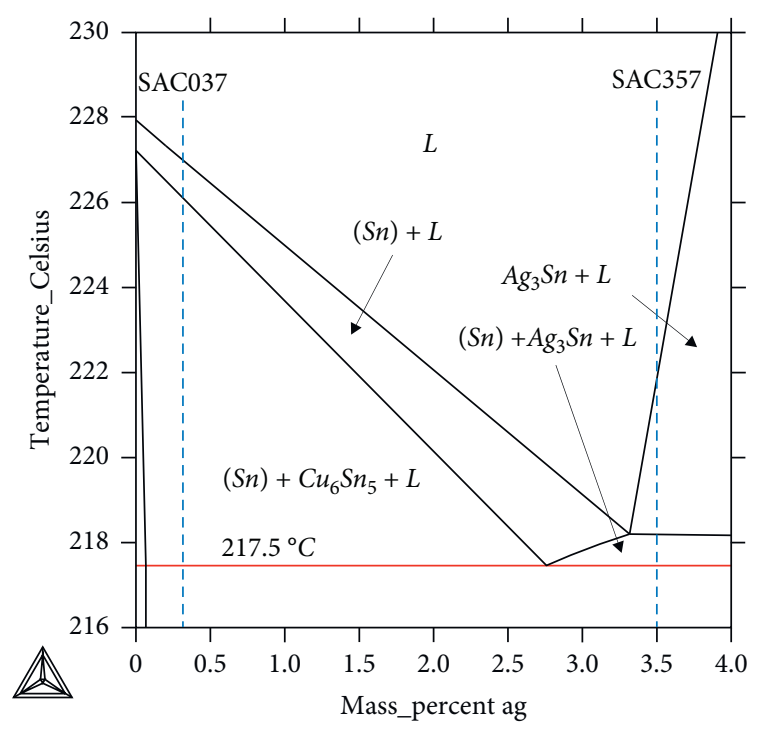

(a)

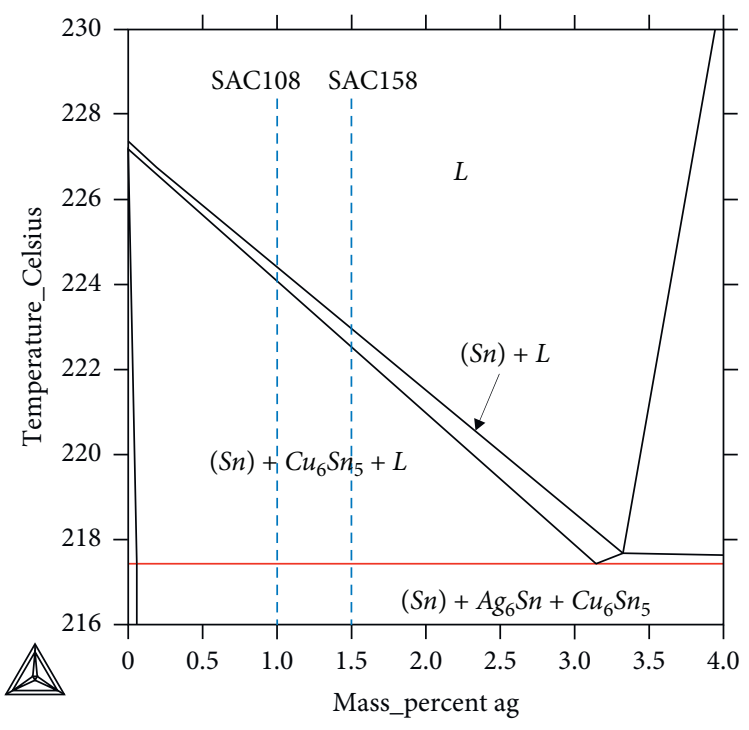

(b)

Figure 6: Vertical section diagrams of $\mathrm{Sn}-0.7 \mathrm{Cu}-\mathrm{xAg}(\mathrm{a})$ and $\mathrm{Sn}-0.8 \mathrm{Cu}-\mathrm{xAg}(\mathrm{b})$ ternary systems.

processes involving melting, such as casting, soldering, and welding. The heat of fusion of the near-eutectic SAC357 alloy was found to be $46 \mathrm{~J} \cdot \mathrm{g}^{-1}$. Hypoeutectic SAC158 and SAC108 alloys had heats of fusion 54.7 and $54.6 \mathrm{~J} \cdot \mathrm{g}^{-1}$, respectively. The highest value $\left(64.4 \mathrm{~J} \cdot \mathrm{g}^{-1}\right)$ had the hypoeutectic low- $\mathrm{Ag}$ solder alloy (SAC037). The enthalpy of fusion $(\Delta \mathrm{H})$ is calculated as the area under the DSC peak by numerical integration [32]. The highest value of the enthalpy of fusion of the SAC037 solder is thus attributed to the highest melting temperature interval of this solder.

3.2. Characterization of Solder Joints. The electrical properties of the solder joints were studied by four-wire electrical resistivity measurements. The results are presented in Figure 7. All solder joints have a low electrical resistivity. The induction soldered joints have an average resistivity of $2.8 \times 10^{-6} \Omega \mathrm{m}$. The reflow soldered joints have an average resistivity of $1.8 \times 10^{-6} \Omega \mathrm{m}$.

A mild decrease of electrical resistivity with increasing $\mathrm{Ag}$ concentration in the alloy is observed for the reflowsoldered joints. This effect, however, is not observed for induction soldered joints. Recently, Rawat and Paul measured the electrical resistivities of Pt [33] and Kim et al. measured the resistivity of the $\mathrm{Sn}-\mathrm{Ag}-\mathrm{Al}$ alloy by four-probe method [34]. The Pt and $\mathrm{Sn}-\mathrm{Ag}-\mathrm{Al}$ electrical resistivities were $1.09 \times 10^{-7}$ and $3.5 \times 10^{-7} \Omega \mathrm{m}$, respectively. These values are approximately 10 times lower than resistivity of the soldered joints investigated in the present work. As the resistivity of $\mathrm{Cu}$ is even lower than the resistivity of the solder, the reason of such increase in electrical resistivity of soldered joints resides in the presence of intermetallic compounds at the substrate-solder alloy interface.

UTS values of soldered joints are compared in Figure 8. There is a notable increase in the solder joints' ultimate tensile strength with increasing silver concentration. The UTS of induction soldered joints is generally higher than

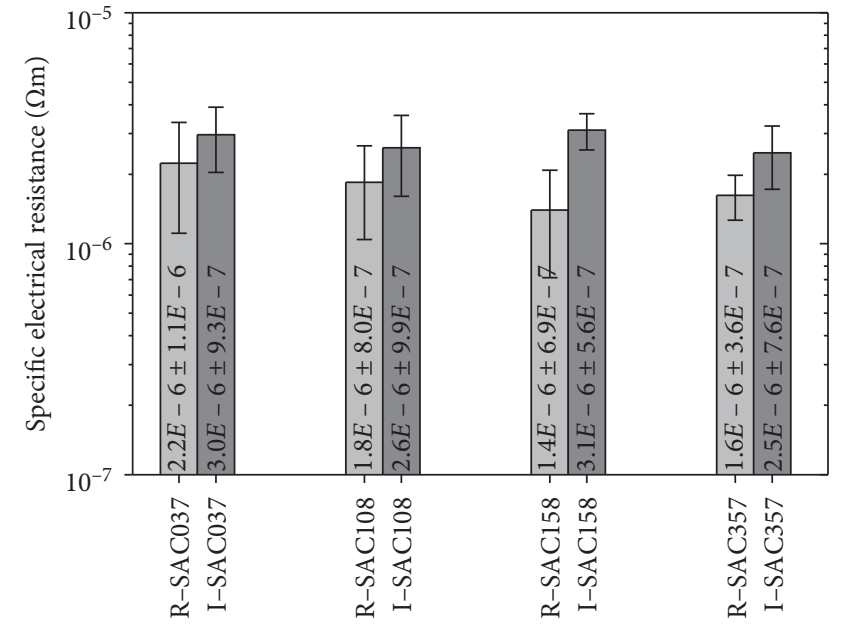

FIgURE 7: Electrical resistivity of soldered joints: prefixes R, reflow soldered by hot plate and I, soldered by induction heating.

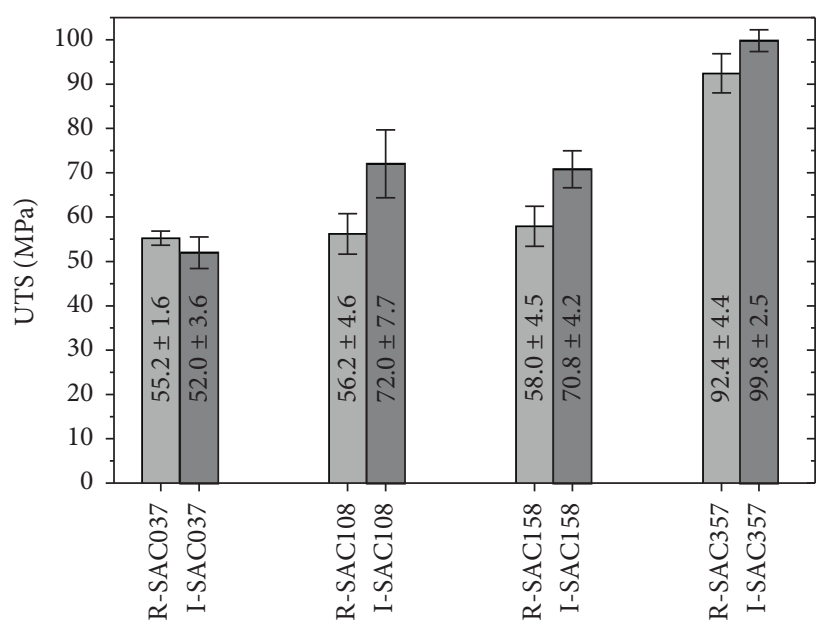

FIGURE 8: Ultimate tensile strength of soldered joints, prefix $\mathrm{R}$, reflow soldered by hot plate and I, soldered by induction heating. 


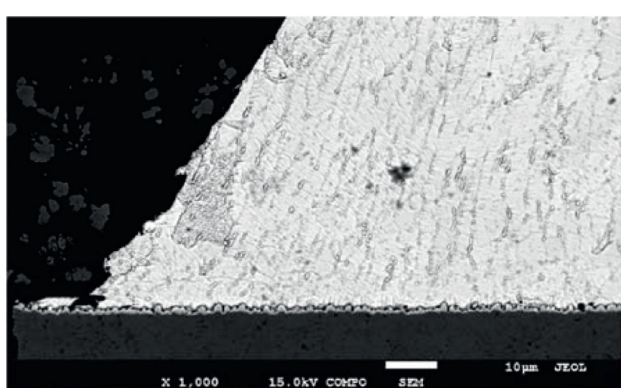

(a)

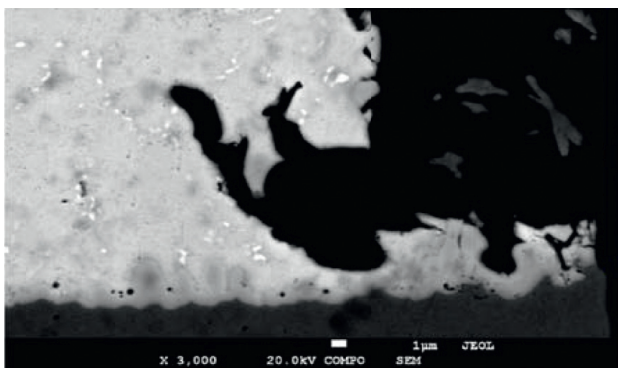

(c)

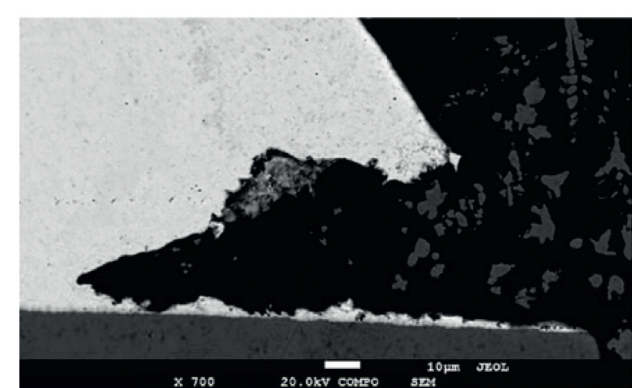

(b)

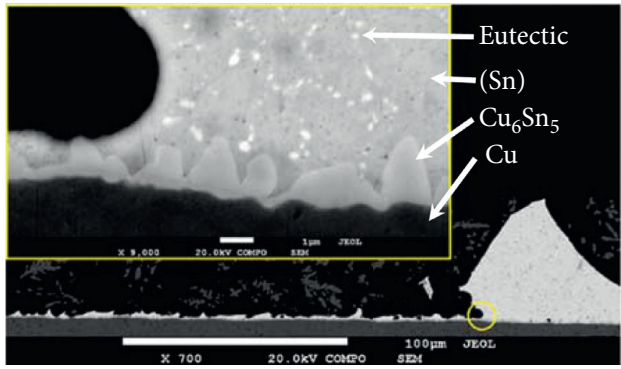

(d)

Figure 9: Microstructures of tested soldered joints made by reflow soldering of SAC038 (a), SAC108 (b), SAC158 (c), and SAC357 (d) solder alloys.

that of reflow soldered joints. The increase in tensile strength is approximately 7, 12, and $15 \mathrm{MPa}$ for SAC357, SAC158, and SAC108 solders, respectively. The only exception is the SAC037 solder where the UTS is lower for the induction soldered joints.

Figures 9(a)-9(d) show the microstructures of the reflow soldered joints after the tensile tests. The figures document the solder-Cu interface of all types of reflow soldered joints. The joints start to detach at the $\mathrm{Cu}$ solder interface. The microstructure of solders consisted of ( $\mathrm{Sn}$ ) grains and eutectic located around the (Sn) grain boundaries [35]. Figure $9(\mathrm{~d})$ shows the microstructure of the reflow soldered SAC357 joint after the tensile test. The inset in Figure 9 shows the area where the crack path started to form. Despite the imminent presence of crack, the microstructure does not seem to be plastically deformed. As such, it is possible that the crack could have been formed without a significant strain. Furthermore, this observation is in agreement with the UTS tests since the reflow soldered joints exhibited a smaller mechanical strength in comparison with their induction soldered counterparts. The exceptions are the joints of the SAC037 solder. In this solder, however, the amount of IMCs was low due to low Ag concentration. Therefore, the mechanical strength of this type of joints was low.

Figure 10 shows the microstructure of the soldered SAC108 joint produced by induction heating after the tensile test. In this case, the crack originated in the solder. The microstructure is affected by plastic deformation (Figure 10(a)). The eutectic is aligned in rows in the direction parallel to crack propagation. Furthermore, the IMCs $\left(\mathrm{Ag}_{3} \mathrm{Sn}\right.$ and/or $\left.\mathrm{Cu}_{6} \mathrm{Sn}_{5}\right)$ are found as small rounded particles that are almost evenly distributed in the microstructure. Figure 10(b) shows the stress distribution in the solder.
According to the FEM analysis, the highest stress was cumulated at the edges. The maximal value of the calculated stress $(94.4 \mathrm{MPa})$ is very close to the measured ultimate tensile stress (99.8 MPa, Figure 8). The edge of the $\mathrm{Cu}$ substrate was plastically deformed at the same place where the maximal stress was found (Figures 10(a) and 10(b)). A similar behavior was observed for the SAC158 and SAC357 soldered joints produced by induction heating (Figures 11(a) and 11(b)). These results suggest that the spreading of the crack during the tensile test was more energy demanding. As such, the mechanical strength of the induction soldered joints was higher. This effect is most obvious for the SAC108 joints, where the gain in mechanical strength was found to be approximately $28 \%$.

The enhancement of mechanical properties of induction soldered joints can be explained by two effects. First is the potentially beneficial effect of the (high frequency) electromagnetic field on the solder microstructure. The application of alternating electromagnetic field during solidification affects the solute and heat transport in the melt, which improves the resulting microstructure [25]. More specifically, it reduces the gradient (imbalance) of the solute within the melt and this is performed by stirring of the melt by electromagnetic force. More homogenous melt is produced by application of electromagnetic field, which promotes a heterogeneous nucleation of primary compounds (IMCs in the present case). Moreover, the IMCs in the melt are further stirred, which prevents their segregation and additional growth. The second effect is that the rotation has a potential of preventing the voids formation at the substrate-solder interface, thereby improving the solder joint reliability. This effect was found to be remarkable for the higher Ag concentration solders, i.e., 


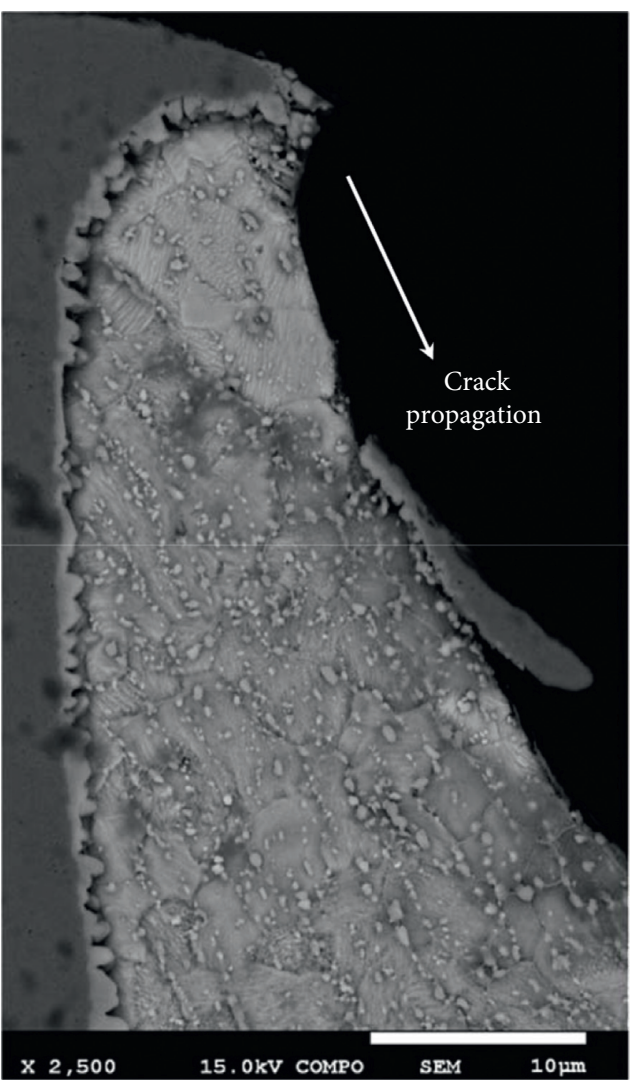

(a)

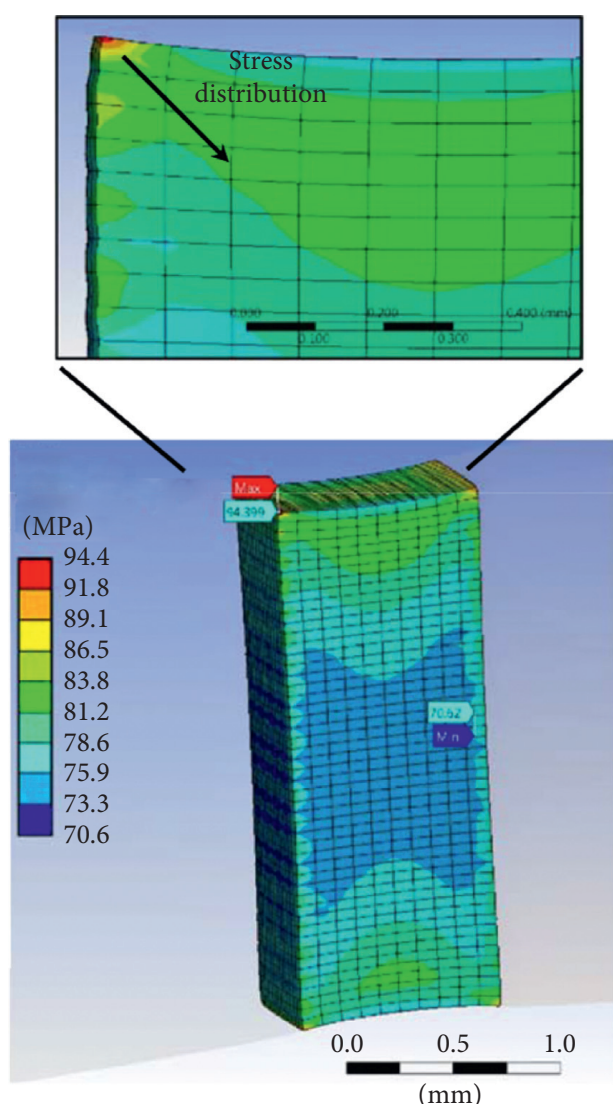

(b)

FIgURE 10: (a) Microstructure of the SAC108 joint soldered by induction heating; (b) FEM analysis of soldered joint area.

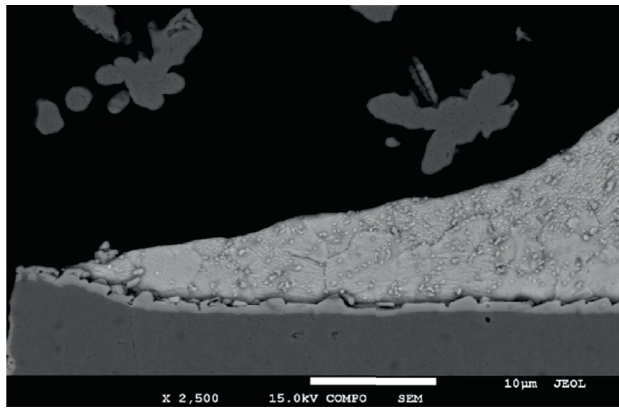

(a)

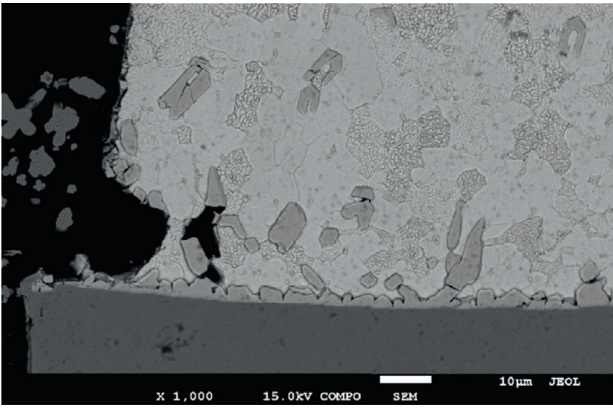

(b)

FIgURE 11: Microstructure of the SAC158 (a) and SAC357joints (b) soldered by induction heating.

TABle 2: Comparative table of the selected findings.

\begin{tabular}{|c|c|c|c|c|c|c|}
\hline \multirow[t]{2}{*}{ Alloy } & \multirow[t]{2}{*}{ Melting temperature $\left({ }^{\circ} \mathrm{C}\right)$} & \multirow[t]{2}{*}{ Heat of fusion $\left(\mathrm{J} \mathrm{g}^{-1}\right)$} & \multicolumn{2}{|c|}{$\begin{array}{l}\text { Electrical resistivity of the joints } \\
\qquad\left(10^{-6} \Omega \mathrm{m}\right)\end{array}$} & \multicolumn{2}{|c|}{$\begin{array}{l}\text { Ultimate tensile strength of the joints } \\
\qquad(\mathrm{MPa})\end{array}$} \\
\hline & & & Reflow soldered & Induction soldered & Reflow soldered & Induction soldered \\
\hline SAC357 & 217.4 & 46.0 & $1.6 \pm 0.4$ & $2.5 \pm 0.8$ & $92.4 \pm 4.4$ & $99.8 \pm 2.5$ \\
\hline SAC158 & $217.6 \div 222.8$ & 54.7 & $1.4 \pm 0.7$ & $3.1 \pm 0.6$ & $58.0 \pm 4.5$ & $70.8 \pm 4.2$ \\
\hline SAC108 & $217.5 \div 224.4$ & 54.6 & $1.8 \pm 0.8$ & $2.6 \pm 1.0$ & $56.2 \pm 4.6$ & $72.0 \pm 7.7$ \\
\hline SAC037 & $217.4 \div 227.9$ & 64.4 & $2.2 \pm 1.1$ & $3.0 \pm 0.9$ & $55.2 \pm 1.6$ & $52.0 \pm 3.6$ \\
\hline
\end{tabular}


SAC357, SAC158, and SAC108, respectively, as can be seen from comparative Table 2. The low Ag solder (SAC038) had a very small amount of the eutectic in the microstructure [35]. As such, the magnetic effect on the IMC distribution was negligible.

The second effect of induction heating is that it may influence the shape and thickness of the intermetallic formed between the substrate and solder. This effect is not directly related to induction heating; however, it is a result of higher temperature employed during soldering. It was found by Wang et al. that, with increasing soldering temperature, the $\mathrm{Cu}_{6} \mathrm{Sn}_{5}$ intermetallic compound at the interface can change its morphology from scallop-type into prism-type [36]. This change needs not to occur in the whole interface area. It is sufficient to be present locally as was already stated by Yang et al. [24]. Yin et al. and Sun et al. observed a fast growth of $\mathrm{Cu}-\mathrm{Sn}$ intermetallic compounds in $\mathrm{Cu} / \mathrm{Sn} / \mathrm{Cu}$ Sandwich system by induction heating $[27,28]$. The rapid evolution of the interfacial IMCs could be caused by electromagnetic stirring and Joule heating [27]. Our results indicate that the IMCs formed at the interface were also affected by induction soldering, because of their different shapes. Any difference in the shape or thickness of the IMC may influence both the resistivity and mechanical strength of soldered joints. The soldering temperature was measured by fine thermocouple connected to the $\mathrm{Cu}$ substrate close to the soldering gap. Due to the relatively short time of induction soldering (see Figure 2) and the strict localization of the generated heat, which was mostly concentrated in the solder, the temperature could not be precisely measured. As such, an actual temperature of liquid solder could have been higher than the recorded one during soldering. The higher temperature might have influenced the IMC growth at the substrate-solder interface.

\section{Conclusions}

The comparative study of reflow and induction soldered joints with four different $\mathrm{Sn}-\mathrm{Ag}-\mathrm{Cu}$ alloys has been conducted in the present work. DSC measurements and thermodynamic calculations of lead-free solders showed that the eutectic temperature was $217.5^{\circ} \mathrm{C}$. The liquidus temperature was between $218.5^{\circ} \mathrm{C}$ and $227.9^{\circ} \mathrm{C}$ in dependence on solder chemical composition.

The induction soldering influenced both the electrical resistivity and mechanical strength of the joints. The FEM analysis of the joints showed that the crack has started to form at the edge of the copper-solder interface and propagated further into the bulk solder. A positive effect on the UTS was found. This effect is attributed to the homogenous distribution of the IMCs within the eutectic in the alloy microstructure. The homogenous distribution of IMC is aided by rotation of liquid solder due to eddy currents and high frequency magnetic field generated during induction heating. This effect was more significant for solders with higher amount of $\mathrm{Ag}$ because of higher concentration of intermetallic particles in the microstructure. Based on the present results, we can conclude that induction soldering is a promising alternative to the reflow soldering process. Because of low equipment costs and simple operation, the induction soldering has broad application prospects.

\section{Data Availability}

The data used to support the findings of the present study are available from the corresponding author upon request.

\section{Conflicts of Interest}

The authors declare that they have no conflicts of interest.

\section{Acknowledgments}

The authors would like to acknowledge the financial support of the grant agency Vega (project no. 1/0151/17) and Slovak Research and Development Agency (project no. APVV-150049). Mr. Peter Kasak is acknowledged for electrical resistivity measurements of soldered joints.

\section{References}

[1] M. F. M. Sabri, N. I. M. Nordin, S. M. Said et al., "Effect of thermal aging on the electrical resistivity of Fe-added SAC105 solder alloys," Microelectronics Reliability, vol. 55, no. 9-10, pp. 1882-1885, 2015.

[2] B. L. Silva, N. Cheung, A. Garcia, and J. E. Spinelli, "Sn-0.7 wt. $\% \mathrm{Cu}-(\mathrm{xNi})$ alloys: microstructure-mechanical properties correlations with solder/substrate interfacial heat transfer coefficient," Journal of Alloys and Compounds, vol. 632, pp. 274-285, 2015.

[3] A. A. El-Daly, A. M. El-Taher, and S. Gouda, "Development of new multicomponent $\mathrm{Sn}$-Ag-Cu-Bi lead-free solders for lowcost commercial electronic assembly," Journal of Alloys and Compounds, vol. 627, pp. 268-275, 2015.

[4] X. Tu, D. Yi, J. Wu, and B. Wang, "Influence of Ce addition on Sn-3.0Ag-0.5Cu solder joints: thermal behavior, microstructure and mechanical properties," Journal of Alloys and Compounds, vol. 698, pp. 317-328, 2017.

[5] M. Drienovsky, L. R. Trnkova, M. Ozvold, I. Cernickova, M. Palcut, and J. Janovec, "Melting behavior and oxidation resistance of Ce-Sn alloy designed for lead-free solder manufacturing," Journal of Thermal Analysis and Calorimetry, vol. 125, no. 3, pp. 1009-1015, 2016.

[6] X. Zhao, Y. Wen, Y. Li, Y. Liu, and Y. Wang, "Effect of $\gamma-\mathrm{Fe}_{2} \mathrm{O}_{3}$ nanoparticles size on the properties of Sn-1.0Ag$0.5 \mathrm{Cu}$ nano-composite solders and joints," Journal of Alloys and Compounds, vol. 662, pp. 272-282, 2016.

[7] Y. Wen, X. Zhao, Z. Chen et al., "Reliability enhancement of Sn-1.0Ag-0.5Cu nano-composite solders by adding multiple sizes of $\mathrm{TiO}_{2}$ nanoparticles," Journal of Alloys and Compounds, vol. 696, pp. 799-807, 2017.

[8] R. M. Shalaby, M. Kamal, E. A. M. Ali, and M. S. Gumaan, "Design and properties of new lead-free solder joints using Sn-3.5Ag-Cu solder," Silicon, vol. 10, no. 5, pp. 1861-1871, 2018.

[9] M. Zhao, L. Zhang, Z.-Q. Liu, M.-Y. Xiong, and L. Sun, "Structure and properties of $\mathrm{Sn}-\mathrm{Cu}$ lead-free solders in electronics packaging," Science and Technology of Advanced Materials, vol. 20, no. 1, pp. 421-444, 2019. 
[10] L. Sun and L. Zhang, "Properties and microstructures of SnAg-Cu-X lead-free solder joints in electronic packaging," Advances in Materials Science and Engineering, vol. 2015, Article ID 639028, 16 pages, 2015.

[11] A. Sharif and Y. C. Chan, "Retardation of spalling by the addition of $\mathrm{Ag}$ in $\mathrm{Sn}-\mathrm{Zn}-\mathrm{Bi}$ solder with the $\mathrm{Au} / \mathrm{Ni}$ metallization," Materials Science and Engineering: A, vol. 445-446, pp. 686-690, 2007.

[12] J. Sopoušek, M. Palcut, E. Hodulová, and J. Janovec, "Thermal analysis of the $\mathrm{Sn}$-Ag-Cu-In solder alloy," Journal of Electronic Materials, vol. 39, no. 3, pp. 312-317, 2010.

[13] M. S. Gumaan, R. M. Shalaby, E. A. M. Ali, and M. Kamal, "Copper effects in mechanical, thermal and electrical properties of rapidly solidified eutectic Sn-Ag alloy," Journal of Materials Science: Materials in Electronics, vol. 29, no. 11, pp. 8886-8894, 2018.

[14] R. M. Shalaby, M. Kamal, E. A. M. Ali, and M. S. Gumaan, "Microstructural and mechanical characterization of melt spun process $\mathrm{Sn}-3.5 \mathrm{Ag}$ and $\mathrm{Sn}-3.5 \mathrm{Ag}-\mathrm{xCu}$ lead-free solders for low cost electronic assembly," Materials Science \& Engineering $A$, vol. 690, pp. 446-452, 2017.

[15] E. Hodúlová, M. Palcut, E. Lechovič, B. Šimeková, and K. Ulrich, "Kinetics of intermetallic phase formation at the interface of $\mathrm{Sn}-\mathrm{Ag}-\mathrm{Cu}-\mathrm{X}(\mathrm{X}=\mathrm{Bi}, \mathrm{In})$ solders with $\mathrm{Cu}$ substrate," Journal of Alloys and Compounds, vol. 509, no. 25, pp. 7052-7059, 2011.

[16] S. Xiao, Z. Wu, L. Liu et al., "Protection against lead-free solder in wave-soldering by $\mathrm{Ti} / \mathrm{TiC}$ coatings prepared by filtered cathodic arc deposition," Surface and Coatings Technology, vol. 312, pp. 7-12, 2017.

[17] S.-S. Deng, S.-J. Hwang, and H.-H. Lee, “Temperature prediction for system in package assembly during the reflow soldering process," International Journal of Heat and Mass Transfer, vol. 98, pp. 1-9, 2016.

[18] M. Li, H. Xu, Ch. Wang, H. S. Bang, and H. S. Bang, "IMC evolution and reliability of lead-free solder bump formed by induction self heat reflow," in Proceedings of the 6th International Conference on Electronic Packaging Technology, Shenzen, China, August 2005.

[19] H.-A. Yang, M. Wu, and W. Fang, "Localized induction heating solder bonding for wafer level MEMS packaging," Journal of Micromechanics and Microengineering, vol. 15, no. 2, pp. 394-399, 2005.

[20] M. Chen, W. Liu, Y. Xi, C. Lin, and S. Liu, "Wafer level bonding using localized radio-frequency induction heating," Science China Technological Sciences, vol. 53, no. 5, pp. 1252-1257, 2010.

[21] M. Li, H. Xu, S.-W. R. Lee, J. Kim, and D. Kim, "Eddy current induced heating for the solder reflow of area array packages," IEEE Transactions on Advanced Packaging, vol. 31, no. 2, pp. 399-403, 2008.

[22] H. Xu, M. Li, J. Kim, and D. Kim, "Local melting and shape controlling of solder joint via induction heating," Journal of Materials Processing Technology, vol. 209, no. 6, pp. 27812787, 2009.

[23] V. L. Lanin, I. I. Sergachou, and V. T. Khotskin, "BGA solder balls formation by induction heating," International Journal of Scientific Research in Knowledge, vol. 2, no. 1, pp. 22-27, 2014.

[24] M. Yang, S. Yang, H. Ji et al., "Microstructure evolution, interfacial reaction and mechanical properties of lead-free solder bump prepared by induction heating method," Journal of Materials Processing Technology, vol. 236, pp. 84-92, 2016.

[25] J. Zhou, D.-P. Lu, K.-M. Liu, Q.-F. Fu, and Z. Zhou, "Influences of alternating magnetic fields on the growth behavior and distribution of the primary $\mathrm{Fe}$ phase in $\mathrm{Cu}-14 \mathrm{Fe}$ alloys during the solidification process," Metals, vol. 8, no. 8, p. 571, 2018.

[26] D. Seehase, C. Kohlen, A. Neiser, A. Novikov, and M. Nowottnick, "Selective soldering on printed circuit boards with endogenous induction heat at appropriate susceptors," Periodica Polytechnica Electrical Engineering and Computer Science, vol. 62, no. 4, pp. 172-180, 2018.

[27] Z. Yin, F. Sun, and M. Guo, "The fast formation of $\mathrm{Cu}-\mathrm{Sn}$ intermetallic compound in $\mathrm{Cu} / \mathrm{Sn} / \mathrm{Cu}$ system by induction heating process," Materials Letters, vol. 215, pp. 207-210, 2018.

[28] F. Sun and Z. Yin, "The interfacial $\mathrm{Cu}-\mathrm{Sn}$ intermetallic compounds (IMCs) growth behavior of $\mathrm{Cu} / \mathrm{Sn} / \mathrm{Cu}$ sandwich structure via induction heating method," Journal of Materials Science: Materials in Electronics, vol. 30, pp. 18878-18884, 2019.

[29] M. Drienovsky, E. Michalcova, M. Pekarcikova et al., IEEE Transactions on Applied Superconductivity, vol. 28, Article ID 6601305, 2018.

[30] A. Dinsdale, A. Watson, A. Kroupa, J. Vrestal, A. Zemanova, and J. Vizdal, COST Action 531-Atlas of Phase Diagrams for Lead-Free Soldering 1, COST Office, Brussels, Belgium, 2008.

[31] K.-W. Moon, W. J. Boettinger, U. R. Kattner, F. S. Biancaniello, and C. A. Handwerker, "Experimental and thermodynamic assessment of $\mathrm{Sn}-\mathrm{Ag}-\mathrm{Cu}$ solder alloys," Journal of Electronic Materials, vol. 29, no. 10, pp. 1122-1136, 2000.

[32] L. Rycerz, "Practical remarks concerning phase diagrams determination on the basis of differential scanning calorimetry measurements," Journal of Thermal Analysis and Calorimetry, vol. 113, no. 1, pp. 231-238, 2013.

[33] P. K. Rawat and B. Paul, "Simple design for Seebeck measurement of bulk sample by 2 -probe method concurrently with electrical resistivity by 4-probe method in the temperature range 300-1000 K," Measurement, vol. 91, pp. 613-619, 2016.

[34] S. H. Kim, K. N. Hui, Y.-J. Kim et al., "Oxidation resistant effects of $\mathrm{Ag}_{2} \mathrm{~S}$ in $\mathrm{Sn}-\mathrm{Ag}$ - $\mathrm{Al}$ solder: a mechanism for higher electrical conductivity and less whisker growth," Corrosion Science, vol. 105, pp. 25-35, 2016.

[35] M. Drienovsky, L. R. Trnkova, M. Martinkovic et al., "Influence of cerium addition on microstructure and properties of $\mathrm{Sn}-\mathrm{Cu}-(\mathrm{Ag})$ solder alloys," Materials Science and Engineering: $A$, vol. 623, pp. 83-91, 2015.

[36] L. Wang, H. Xu, M. Yang, M. Li, and Y. Fu, "Dramatic morphological change of interfacial prism-type $\mathrm{Cu}_{6} \mathrm{Sn}_{5}$ in the $\mathrm{Sn} 3.5 \mathrm{Ag} / \mathrm{Cu}$ joints reflowed by induction heating," in Proceedings of the International Conference on Electronic Packaging Technology \& High Density Packaging, pp. 10-13, Beijing, China, August 2009. 